\title{
Edifícios de habitação em áreas urbanas consolidadas: Rue des Suisses, e Casarão do Carmo
}

\author{
Collective Housing Projects in Built-up Urban Areas: Rue des \\ Suisses, and Casarão do Carmo
}

Prof. Dr. Caio Flávio Lamboglia de Araujo

Universidade Presbiteriana Mackenzie

Contato: greenwich@uol.com.br

\begin{abstract}
This paper aims to study two collective housing projects situated in built-up areas: Rue des Suisses, by Herzog \& de Meuron and Casarão do Carmo by Hector Vigliecca. Through the study of these two proposals, this paper seeks to systematize the design strategies employed by the two offices to implement new collective housing projects in the traditional city, establishing a dialogue between the new proposal and their immediate urban context.
\end{abstract}

Keywords: Collective Housing, metropolis, urban context.

Edifícios de habitação em áreas urbanas consolidadas: Rue des Suisses, e Casarão do Carmo

A contínua construção e resignificação de espaços urbanos na contemporaneidade coloca inúmeras dificuldades a serem pensadas por arquitetos e urbanistas, especialmente nos países em desenvolvimento. Entre elas destacam-se o abandono das áreas centrais e a difusão urbana acompanhados pela construção em grande escala de edifícios com pouca ou nenhuma relação com a cidade existente. Esse tipo de desenvolvimento urbano tem contribuído para a transformação de grande parte da cidade em territórios

\section{Resumo}

Este trabalho se propõe a estudar dois projetos de habitação propostos para áreas urbanas consolidadas - o Conjunto Habitacional Rue des Suisses do escritório Herzog e De Meuron e o Conjunto Casarão do Carmo, do escritório Hector Vigliecca \& Associados - no que se refere à relação entre o edifício e a cidade. Foram analisadas suas implantações e fachadas bem como seus espaços coletivos com o objetivo de compreender e sistematizar as estratégias projetuais propostas nos dois casos para organizar o edifício em relação ao tecido urbano existente.

Palavras-chave: Habitação, metrópole, contexto urbano. sub-aproveitados, com espaços públicos sem significado e não apropriados por seus habitantes.

$\mathrm{O}$ adensamento populacional em áreas consolidadas, alcançado por meio de projetos de habitação, parece ser uma solução para um melhor aproveitamento desses territórios urbanos, pois pode otimizar o uso de infra-estruturas presentes e, ao trazer um maior número de habitantes, diminuir a necessidade de deslocamentos urbanos de grande distância, um dos maiores problema da metrópole contemporânea. As estratégias de implantação de edifícios novos nessas áreas já densamente construídas, se pensadas de modo a reconhecerem e incorporarem elementos pré-existentes, podem ser alternativas 
possíveis para a recuperação da identidade desses territórios.

Este trabalho se propõe a analisar dois projetos contemporâneos de habitação, inseridos em malha urbana consolidada, que demonstram uma preocupação com as questões discutidas acima. São eles: o Conjunto Habitacional Rue des Suisses, de Herzog \& de Meuron, de 1999 (figura 1) e o Conjunto Habitacional Casarão do Carmo, de Hector Vigliecca de 2002 (figura 2). Os dois projetos se encontram em territórios urbanos densamente edificados e apresentam respostas projetuais ao desafio de se construir habitação em áreas urbanas.

Embora o Conjunto Habitacional Casarão do Carmo encontre-se apenas parcialmente construído e não seja possível sua análise baseada no edifício propriamente dito, seus desenhos e maquetes já informam a idéia de cidade subjacente no projeto e as soluções buscadas pelo arquiteto para inserir o edifício em contexto urbano densamente edificado.

A cidade consolidada e sua relação com o edifício tem sido tema de interesse de diversos estudiosos, sobretudo desde a segunda metade do século XX. Autores como Aldo Rossi (1995), Colin Rowe (1984) e Jane Jacobs (1993) defenderam a importância de se entender a cidade como construção coletiva e abriram caminho para um maior reconhecimento de seu caráter plural, fragmentário e híbrido. Em linha com esses autores, este trabalho parte do entendimento do edifício como fragmento, capaz de, ao entrar em síntese com a dinâmica urbana, modificá-la em pequena escala.

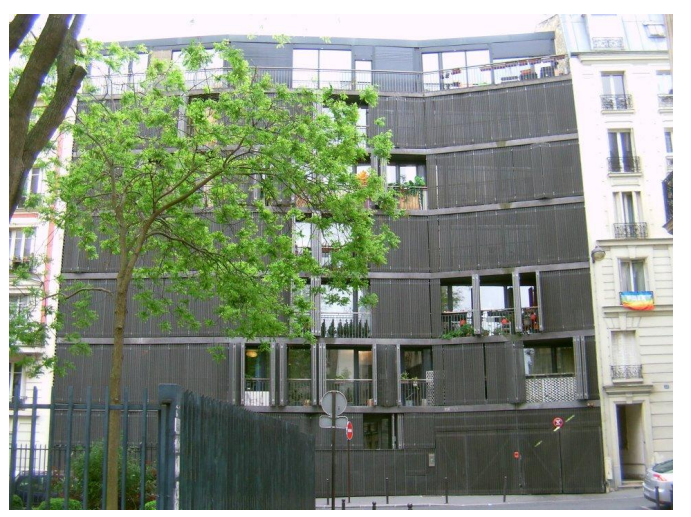

Figura 1 - Rue des Suisses - Fonte: Fotografia de Aline Uara, 2012

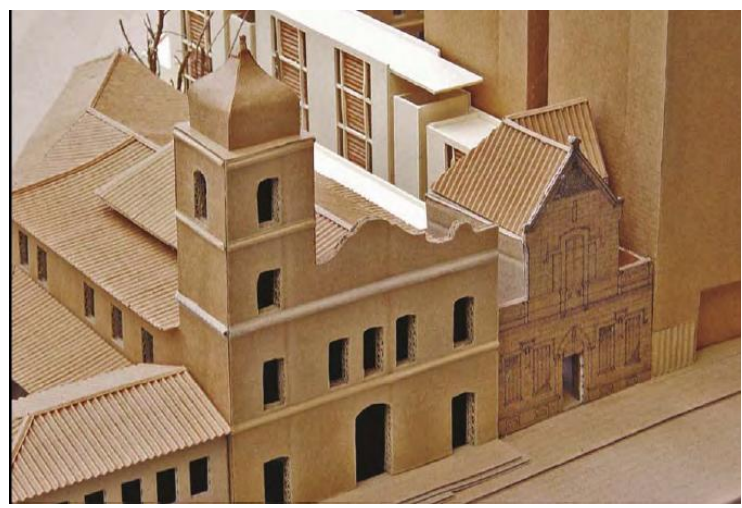

Figura 2- Casarão do Carmo - Fonte: Vigliecca \& Associados

Desse modo, a proposta é discutir a construção de cidade através do projeto do edifício, por meio do estudo das soluções de projeto adotadas para acomodá-lo em contextos urbanos consolidados. O objetivo da discussão é entender como são feitas as articulações entre projeto e pré-existências urbanas nos dois edifícios estudados e sistematizar estratégias projetuais que possam oferecer alternativas que diferem do edifício no centro do lote.

\section{Rue des Suisses}

O conjunto habitacional Rue des Suisses, projetado pelo escritório Herzog e de Meuron, configura-se como um conjunto de edifícios com características formais heterogêneas, apresentando uma variedade tipológica, de materiais e de estratégias projetuais que se adicionam, sobrepõem e contrastam entre si.

Localizado no $14^{\circ}$ arroindissement de Paris e contendo abriga 57 unidades (mais do dobro de 
unidades que o Casarão do Carmo), o projeto foi o vencedor de um concurso em 1996, proposto pela Régie Immobilière de la Paris (RVIP), agência francesa de habitação social, que segundo Jackson (2002), é renomada por suas proposições inovadoras.

O projeto, implantado em um terreno longitudinal em formato de $\mathrm{Y} \mathrm{e}$ com fachadas voltadas para duas ruas Rue des Suisses e Rue Jonquoy - consiste em cinco blocos (figura 3), com a seguinte configuração:
- Dois edifícios entre medianeiras (edifício $a$, com 34 apartamentos, com frente para a Rue des Suisses e edifício $b$, com 8 apartamentos, com frente para a Rue Junquoy)

- Um bloco horizontal de três pavimentos no interior do quarteirão com 15 apartamentos (edifício $c$ )

-Duas pequenas casas (edifícios $d$ e $e$ ) com dois dormitórios, também no interior do quarteirão.

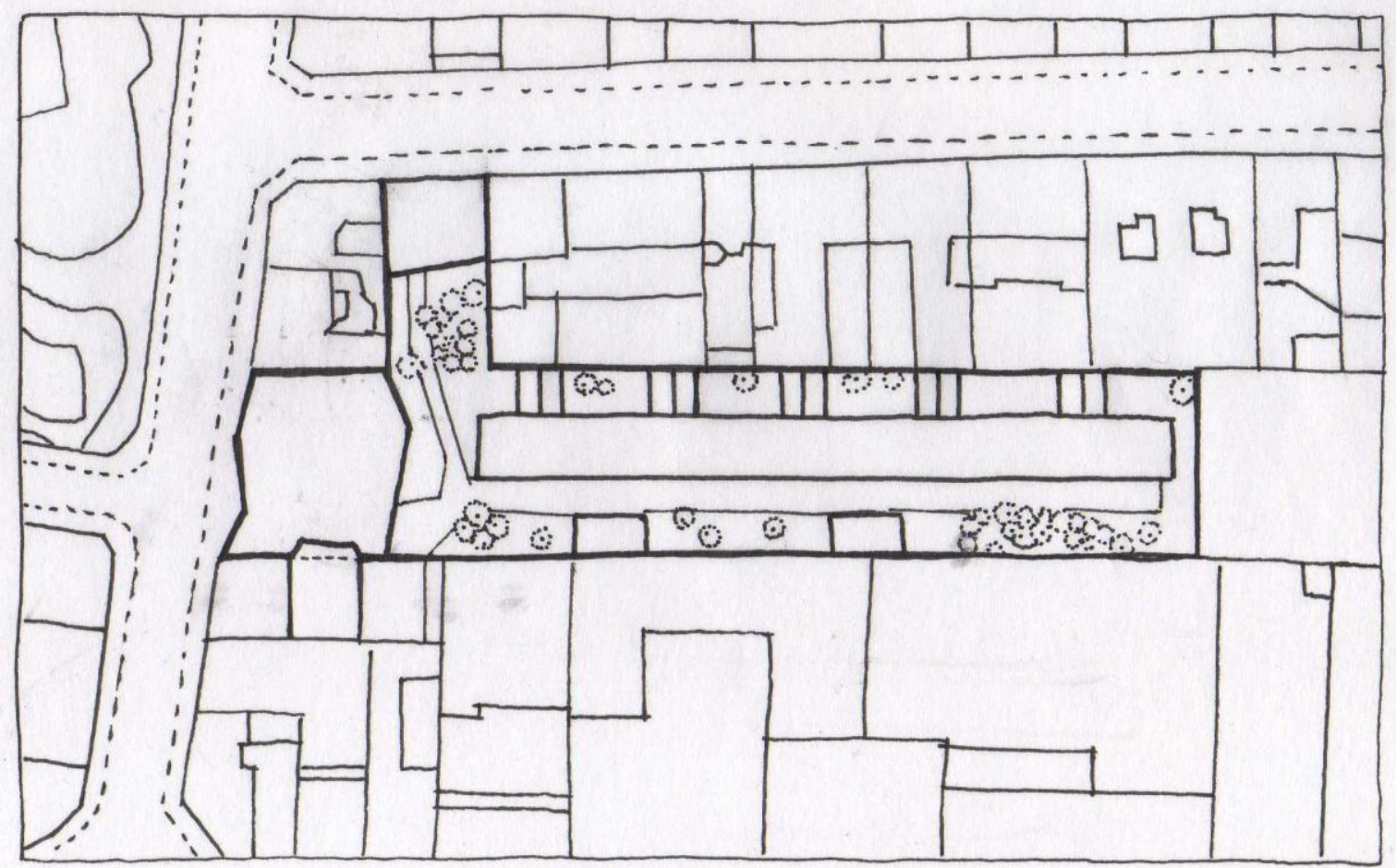

Figura 3: Implantação dos edifícios - Fonte: Desenho de Caio Flavio Araujo, 2012

Essa diversidade de tipologias proporciona ao conjunto uma gama de soluções projetuais variadas e uma complexidade de relações dos edifícios entre si e com as pré-existências. De fato, alguns autores chegam a caracterizar o projeto como materialização de uma "gramática urbana" (FernándezGaliano, 2001) - no sentido de apresentar diferentes maneiras de se construir cidade - ou como um exemplo de heterotopia (Duboy, 2001) relacionando o projeto ao conceito foucaultiano da justaposição, em um mesmo lugar, de espaços a princípio incompatíveis e contraditórios.

Uma das principais características comentadas por esses autores é a relação do projeto com o contexto onde está localizado, que acontece de maneira mais explícita nos edifícios a e b (figuras 4 e 5).

Edifício B 


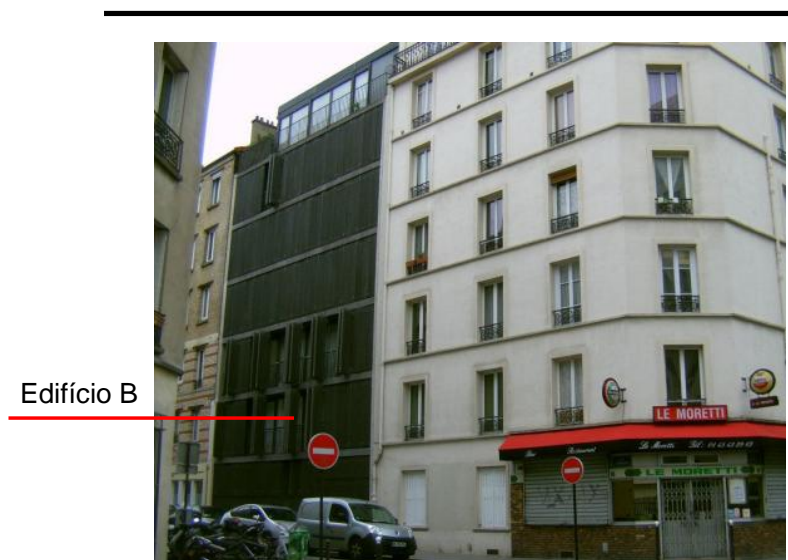

Figura 4: Edifício B - Fotografia de Aline Uara, 2012

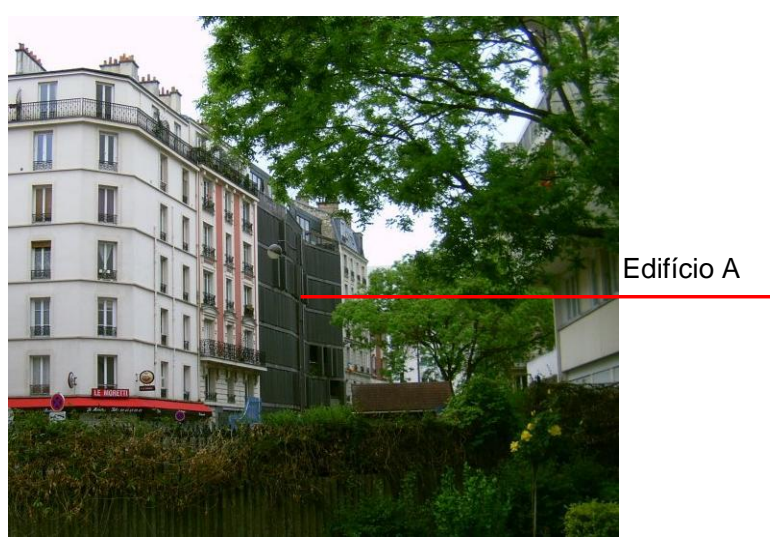

Figura 5: Edifício A - Fotografia de Aline Uara, 2012

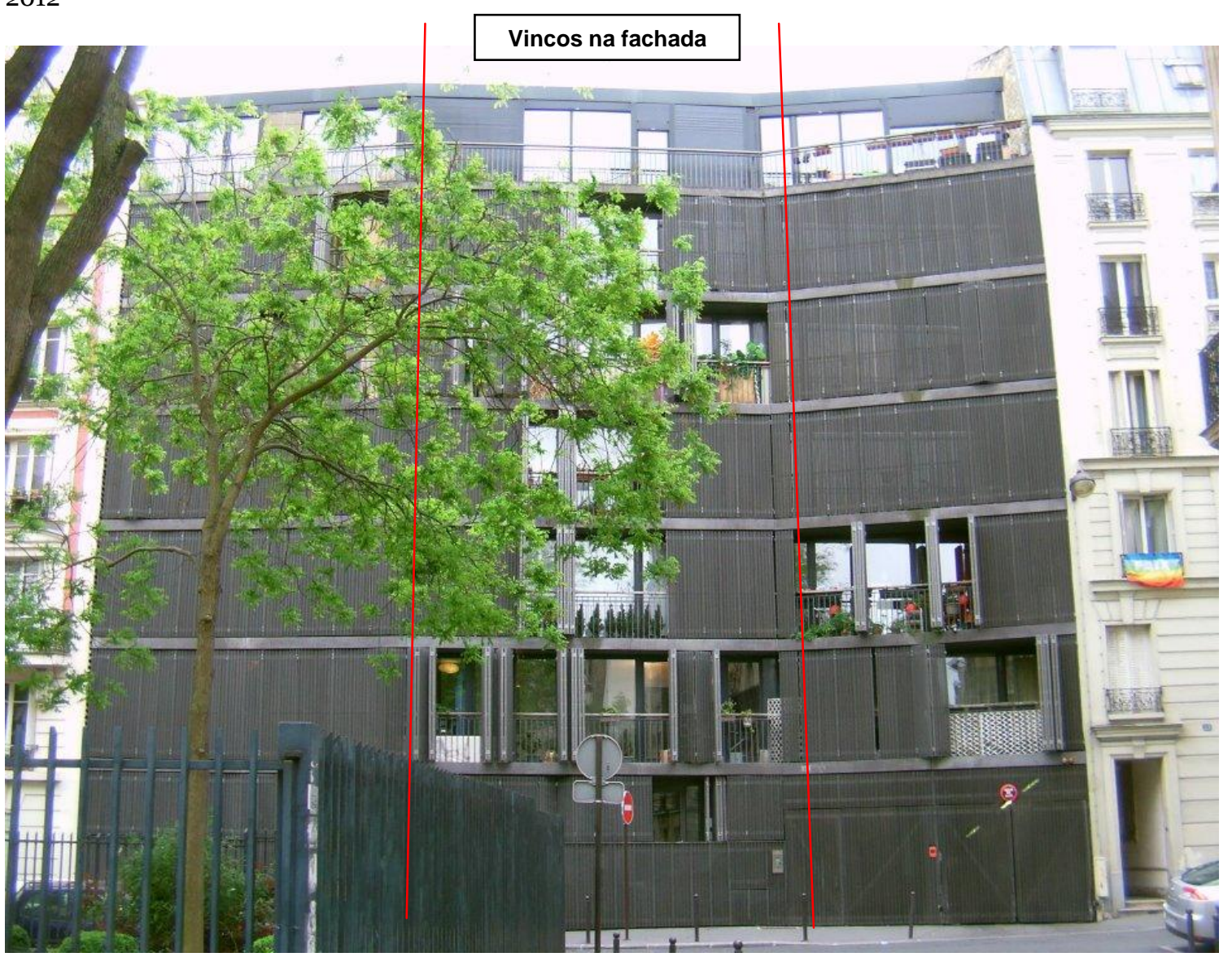

Figura 6 - Fachada Rue des Suisses - Fonte: Fotografia de Aline Uara, 2012
Esses edifícios, com fachadas alinhadas com a rua, foram concebidos como blocos contínuos ao tecido urbano parisiense, composto, em grande parte, por conjuntos habitacionais de sete andares. A nova proposta segue esse alinhamento e gabarito, preenchendo os terrenos entre medianeiras nos quais está implantada. Os dois blocos, desse modo, não se colocam como objetos isolados, mas como elementos incorporados de maneira contínua à cidade existente.

Apesar dessa característica, o edifício proposto para a Rue des Suisses introduz novos elementos em sua volumetria que o diferencia de seus edifícios vizinhos. A característica formal mais marcante é uma "dobra" para dentro, tanto na parte frontal quanto na parte posterior do edifício configurando dois vincos verticais nas fachadas. 
Essas dobras podem ser entendidas como uma marca da presença da Rue Pauly, na frente da qual se encontra $o$ acesso principal ao conjunto ou como um direcionamento, em uma fachada metálica sem demarcações de acesso, à entrada principal (figura 6 - em vermelho). Ao se observar a implantação desse edifício, também é possível entender essa dobra como uma estratégia de acomodação do edifício entre os dois edifícios de habitação pré-existentes, de larguras distintas. Essa acomodação é feita encostando o novo bloco apenas onde existem as medianeiras: de maneira integral no edifício da esquerda e reconhecendo o pátio presente no edifício da direita (figura 7 - em verde).

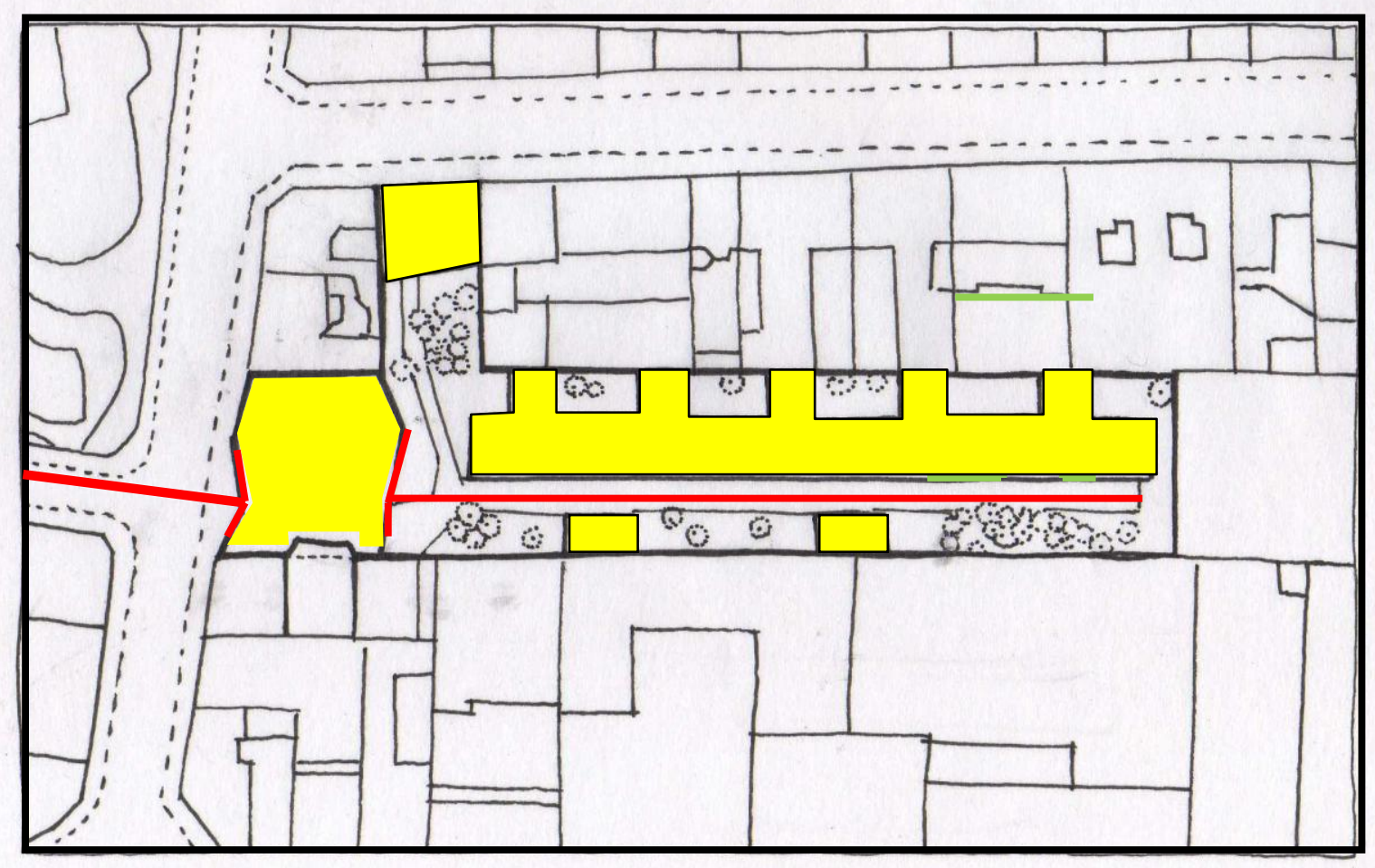

Figura 7 - Implantação dos Edifícios Fonte: Desenho de Caio Flavio Araujo

Quanto ao material, todas as fachadas dos edifícios entre medianeiras se caracterizam por venezianas verticais em alumínio perfurado, pintadas de cinza escuro, e lajes horizontais aparentes na mesma cor. Quando fechadas, essas venezianas - com altura de piso a teto, exceto no pavimento térreo, com meia altura (figura 8) conferem aos edifícios uma aparência contínua e homogênea. Ao se abrirem, correndo em trilhos horizontais, proporcionam configurações descontínuas e aleatórias.

Uma varanda faz a separação entre as venezianas e os panos de vidro de chão a teto que fecham o apartamento. Esse esquema, presente desde $o$ piso térreo até $o$ sexto pavimento, se altera no sétimo, que é recuado, com varanda aberta, e com venezianas junto às janelas com um mecanismo vertical em vez de horizontal. Essa característica reforça sua condição de último andar diferenciado, traço presente nos edifícios contíguos e, de fato, em grande parte dos edifícios de habitação de Paris. 


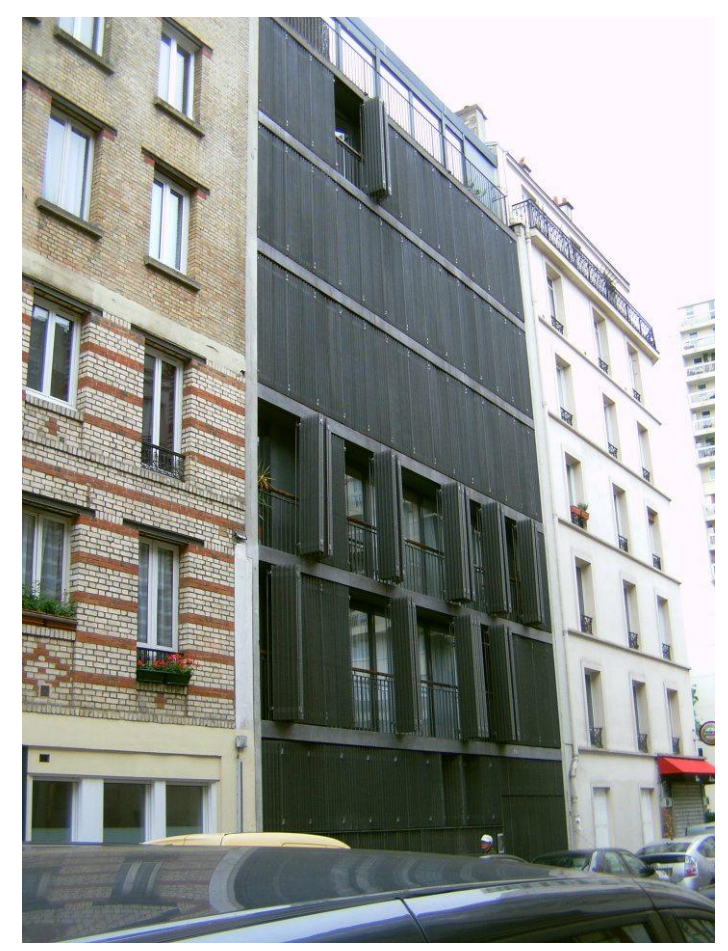

Figura 8 - Fachada Rue Junquoy - Fonte: Fotografia de Aline Uara, 2010

O andar térreo do bloco $a$ contém o3 apartamentos, sendo um de área maior, com 2 dormitórios, voltado para a rua e dois de menor área (1 e 2 dormitórios), voltados para o interior do quarteirão, além de um dos acessos ao conjunto e o acesso à garagem, localizada no subsolo do conjunto.

Os andares seguintes contêm cinco apartamentos por andar, sendo duas unidades com 1 dormitório (uma voltada para a rua e outra voltada para o interior do quarteirão), duas unidades com 2 dormitórios (no mesmo esquema) e 1 unidade com 03 dormitórios com janelas para a rua e para o interior do quarteirão.

O bloco $b$ apresenta algumas diferenças, tanto em relação à fachada quanto às plantas dos andares. Devido à sua menor área, contém um apartamento de 2 dormitórios (exceto no andar térreo, com 1 dormitório), planta com salas integradas e janelas voltadas para a rua e para o interior do quarteirão, com o mesmo sistema de varandas presente no bloco a. No que se refere à fachada, o bloco b, por ser mais curto e não conter o acesso de veículos, não apresenta os vincos verticais característicos do bloco a (figura 8). Apesar da morfologia distinta, os materiais, assim como sistema de ventilação e iluminação são os mesmos nas duas fachadas.

O edifício implantado no interior do quarteirão (bloco c - figura 9) apresenta uma estratégia distinta. Segundo os próprios arquitetos (2011), o bloco foi pensado de maneira a não competir com as empenas cegas dos edifícios pré-existentes, de costas ao interior do quarteirão. A proposta é um volume longitudinal de três andares (dessa maneira, mais baixo do que os blocos $a$ e $b$ e do que os edifícios préexistentes) que abriga apartamentos maiores, de 2 e 3 dormitórios, sem acesso direto para a rua.

Esse edifício, assim como os blocos $a$ e $b$, também se caracteriza pela presença de venezianas como elemento de fechamento, conferindo à fachada uma característica aleatória. Desta vez, no entanto, elas são de madeira e correm verticalmente, se enrolando à maneira de uma escrivaninha antiga e configurando, assim como no bloco $a$ também uma quebra na ortogonalidade, desta vez não mais vertical, mas horizontal. Neste momento, é nítida a intenção dos arquitetos em contrapor os dois edifícios, tanto por meio da dicotomia horizontal / vertical (venezianas e o próprio edifício), reto / curvo (na morfologia das fachadas), metal (nos blocos $a$ e $b$ ) / madeira (no edifício $c$ ).

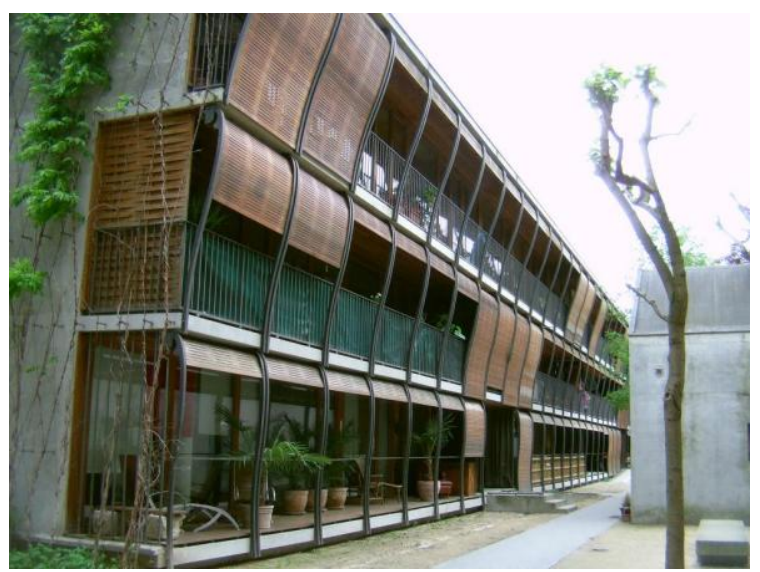

Figura 9- Bloco c. Fonte: Fotografia de Aline Uara, 2012 
Outra contraposição entre as duas tipologias empregadas diz respeito à questão do contato do edifício com o solo e com os outros blocos. Enquanto nos blocos $a$ e $b$ o contato é integral tanto com as medianeiras dos edifícios existentes quanto com o solo, conformando blocos mais contidos, o bloco $c$ parece flutuar, sendo ligeiramente elevado sobre o solo, de modo a proteger a privacidade do morador. Além disso, as laterais desse bloco, diferentemente das medianeiras, não se encostam em nenhum edifício, evidenciando um caráter objetual e destacado ao edifício e uma maior independência do tecido urbano.
Ao se observar as plantas e os cortes do bloco, percebe-se, entretanto, que essa independência da malha urbana é apenas aparente. O pavimento térreo ancora o edifício à cidade através de volumes encostados no limite do terreno e alinhados com os edifícios préexistentes. Esses volumes, em concreto aparente e com telhados de duas águas, abrigam as áreas molhadas dos apartamentos desse pavimento e configuram pequenos pátios que também se alinham com os vazios existentes nos edifícios contíguos ao conjunto (figura $10 \mathrm{em}$ vermelho tracejado).

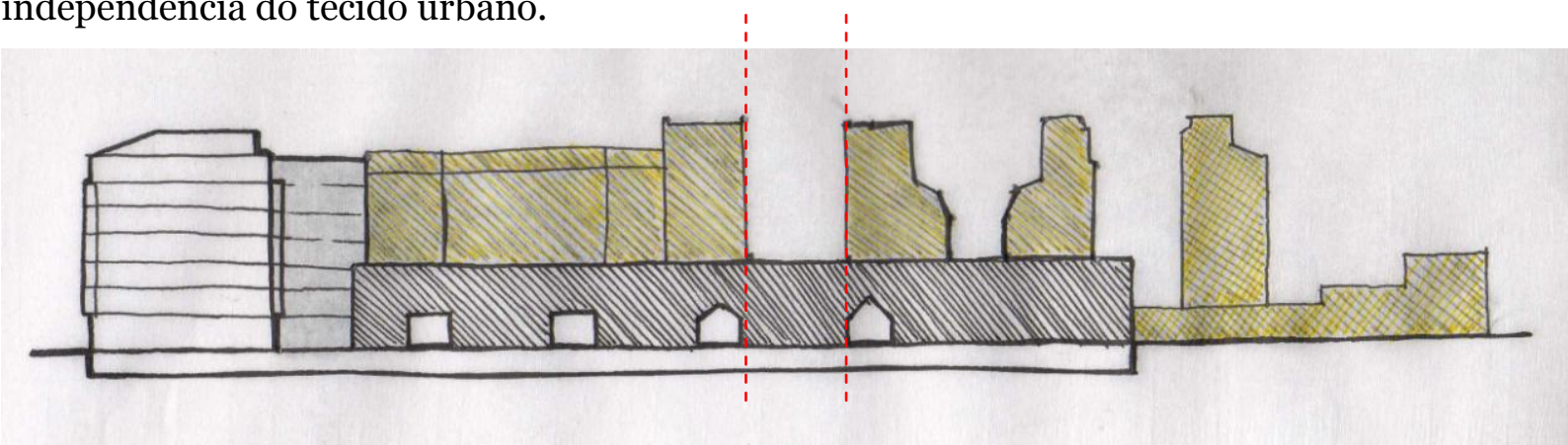

Figura 10 - Corte esquemático - Fonte: Desenho de Caio Flavio de Araujo

também no interior do quarteirão, de

Essa implantação, que se define de acordo com o alinhamento do edifício com as pré-existências, proporciona configurações diferentes a cada apartamento, o que revela uma organização da arquitetura deste volume também sujeita às contingências urbanas.

Os apartamentos se organizam nesse bloco de maneira ortogonal e planta mais tradicional do que a planta dos apartamentos do bloco $a$. De característica retangular, configuram, assim como nos edifícios entre medianeiras, uma varanda ao longo do edifício, entre o fechamento em vidro e as venezianas de madeira. Nos andares superiores as unidades são acessadas por caixas de escada a cada dois apartamentos, aumentando de área gradativamente por meio de um escalonamento invertido, do menor para o maior a partir do térreo (figura 9).

Além dos edifícios a, b e c, os arquitetos propuseram a implantação, duas pequenas casas (figura 9). São volumes independentes do restante do conjunto e remetem, ao mesmo tempo, aos elementos localizados na parte posterior do bloco $c$ e à tipologia casa isolada. Esses pequenos elementos introduzem mais um material, o concreto aparente, à gama já presente nos outros edifícios. Dessa maneira, cada tipologia é identificada com um material diferente (metal nos edifícios entre medianeiras, madeira no volume semiindependente, concreto nas casas).

O acesso ao conjunto é dado pelos pavimentos térreos dos blocos a e $\mathrm{b}$, de onde se tem acesso aos apartamentos desses edifícios (à maneira tradicional parisiense) e ao pátio interno. A circulação interior ao quarteirão segue a configuração longitudinal do terreno, só interrompida visualmente pela presença das casas isoladas, que, assim como nos volumes posteriores do edifício c, conformam pequenos pátios, ou áreas de estar, ao ar livre. 


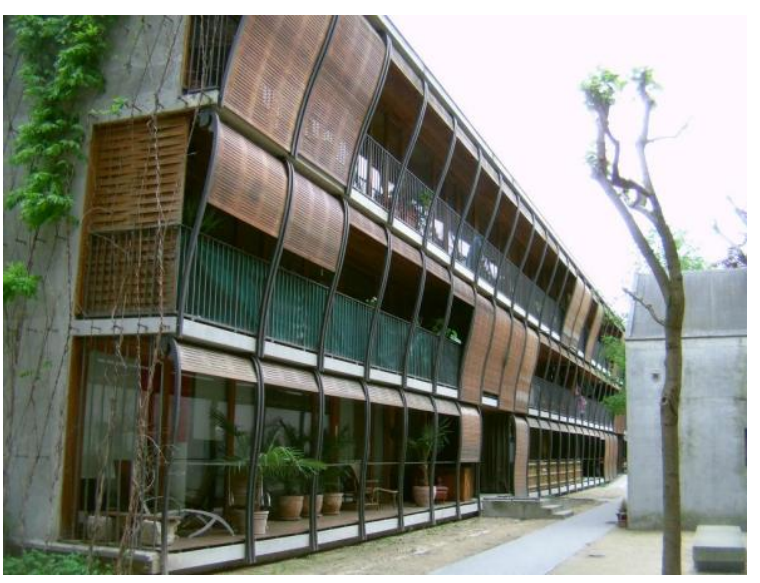

Figura 11 - Blocos C e D - Fonte: Fotografia de Aline Uara, 2012

O paisagismo confere a essa área um caráter bucólico, quase anti-urbano e que pode ser entendido como um alívio das obrigações e formalidades da cidade, representadas pelos blocos $a$ e $b$, mais contidos e urbanos. Para acentuar esse caráter, o bloco $c$ apresenta uma malha de cabos em suas fachadas laterais e posterior, o que possibilita que trepadeiras e videiras escalem o edifício (figura 11).

É tentador interpretar esse projeto como uma contraposição entre duas estratégias de implantação: uma contextual, representada pelos blocos $a$ e $b$ e outra independente, representada pelos bloco $c, d$ e $e$. Essa interpretação, entretanto, é uma maneira de se compreender a obra que talvez não dê conta da complexidade de idéias presentes no projeto. Existem elementos opostos, por certo, mas também características comuns aos três blocos.

Talvez uma metáfora mais apropriada para descrever as estratégias projetuais presentes neste projeto seja, em vez de contraposição, diálogo. Diálogos às vezes concordantes, às vezes discordantes, mas sem dúvida estabelecendo relações entre tipologias, materiais, implantações e estratégias projetuais por meio de similaridades e oposições que conversam entre si e com as pré-existências.

\section{2 - Casarão do Carmo}

A segunda proposta a ser estudada neste trabalho é o projeto de Hector Vigliecca para o Conjunto Habitacional Casarão do Carmo. O projeto, encomendado pela $\mathrm{COHAB}$, localiza-se entre as Ruas do Carmo e a Rua Tabatingüera, na região central da cidade de São Paulo, próxima à Catedral da Sé.

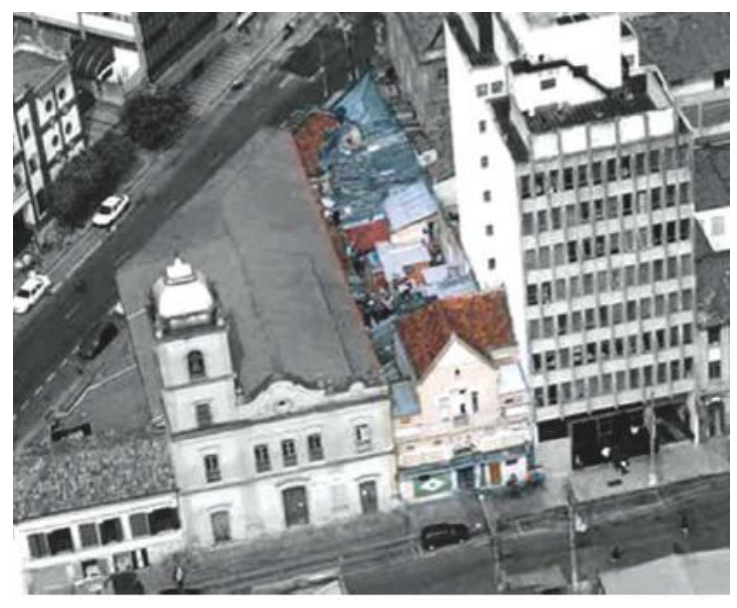

Figura 12 - Situação Original - Fonte: Vigiecca \& Associados

Infelizmente a proposta de Vigliecca se encontra apenas parcialmente construída, devido a uma interrupção das obras por questões de patrimônio histórico relativos à igreja do Carmo, localizada no terreno ao lado. Dessa maneira, a análise será feita com base em desenhos, mapas e maquetes.

O conjunto foi projetado para abrigar 25 famílias que viviam em um cortiço que ocupava um lote de configuração longitudinal, morfologia semelhante ao lote do projeto para a Rue des Suisses, descrito acima. A proposta de Vigliecca para o local é, segundo BARROS et al.(2009, p.11), "o resultado de um ajuste inventivo entre gabaritos, divisas, articulações possíveis $e$ desejadas e espaço público da rua”.

A proposta se configura basicamente pela implantação de dois edifícios residenciais com capacidade de abrigar as 25 famílias e a proposta de manutenção da casa paroquial da Igreja do Carmo, também ocupada pelo cortiço, como parte do projeto. De acordo com 
essa configuração, a entrada e a fachada principal do conjunto, à semelhança do projeto de Herzog e de Meuron, também se localizam no menor lado do terreno, neste caso voltado para a Rua do Carmo.

A fachada principal, entretanto, consiste na reabilitação de um edifício pré-existente. Por meio dessa estratégia, o a nova proposta se encontra "escondida" atrás desse edifício, que tem seu uso revertido para, além da entrada principal do conjunto, um espaço para reuniões, festas e outros eventos a ser utilizado pelos habitantes do conjunto. Os novos edifícios habitacionais, dessa maneira, só seriam percebidos após a entrada no conjunto, pela Rua do Carmo.

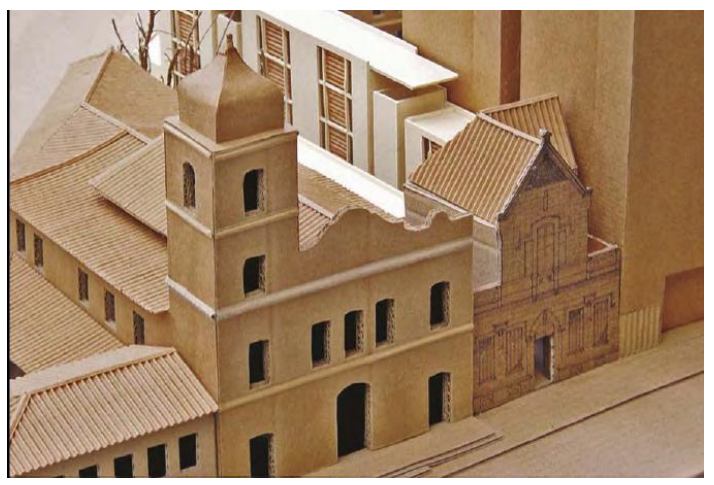

Figura 13 - Proposta Hector Vigilecca

Fonte: Vigiecca \& Associados

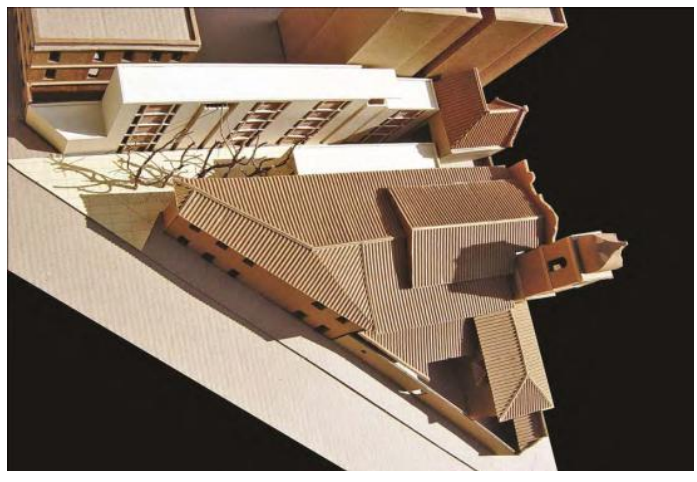

Figura 14- Implantação Fonte: Vigiecca \& Associados

Esses edifícios se organizam em duas lâminas paralelas, encostadas nos limites do terreno e ajustados de maneira a seguir o mesmo gabarito dos edifícios contíguos: cinco andares, no caso do edifício à direita (edifício $f$ ), e três andares, no caso do edifício à esquerda (edifício $g$ ), encostado na igreja. $\mathrm{O}$ edifício $f$ contém 20 apartamentos, enquanto o edifício $b$, mais curto e de menor altura, devido à existência de janelas da igreja voltadas para o terreno, contém um numero menor de unidades, apenas 6.

A implantação dos dois edifícios, de forma paralela e encostada nos limites laterais do lote, abre, no interior do quarteirão, uma passagem de pedestres. Essa passagem, à semelhança do projeto para a Rue des Suisses, possibilita a circulação principal do conjunto, que dá acesso às caixas de escada de cada bloco que servem dois apartamentos por andar.

A circulação interna de pedestres, no entanto, apresenta uma peculiaridade que a distingue do edifício parisiense: foi concebida como um espaço não apenas coletivo, mas também público, de acesso irrestrito tanto aos moradores quanto aos pedestres que passam na região, ligando duas ruas e criando, além de uma passagem, também uma área de estar urbana, de uso dos moradores e da população em geral.

Segundo BARROS et al. (ibid.) essa estratégia garante ao habitante do conjunto a possibilidade de, apesar de estar no interior do quarteirão, morar de frente para uma rua, nesse caso, uma rua de pedestres. Os futuros moradores do conjunto se opuseram a essa proposta, dada a preocupação com a violência urbana na cidade de São Paulo, e propuseram o fechamento do conjunto para não moradores.

Devido à não implantação do projeto, é impossível avaliar com precisão o que aconteceria se $o$ fechamento realmente ocorresse. Possivelmente o projeto perderia

grande parte de sua força e potência de transformação urbana da área. Apesar disso, o projeto do Casarão do Carmo continua a ser uma resposta de projeto do arquiteto a um problema evidente na cidade - a ausência de espaços públicos de qualidade - e uma possibilidade de ampliar sua discussão.

Com relação à unidade habitacional, o conjunto, diferentemente do projeto de Herzog e de Meuron, não propõe diferentes apartamentos para diferentes famílias. As plantas das 
unidades são praticamente idênticas e pensadas de modo que, em um espaço mínimo, pudessem abrigar as famílias de maneira qualificada. Essa área mínima, de acordo com BARROS et al. (ibid.), seria compensada pela área de uso coletivo, no interior do quarteirão, que funcionaria como área suplementar ao apartamento.

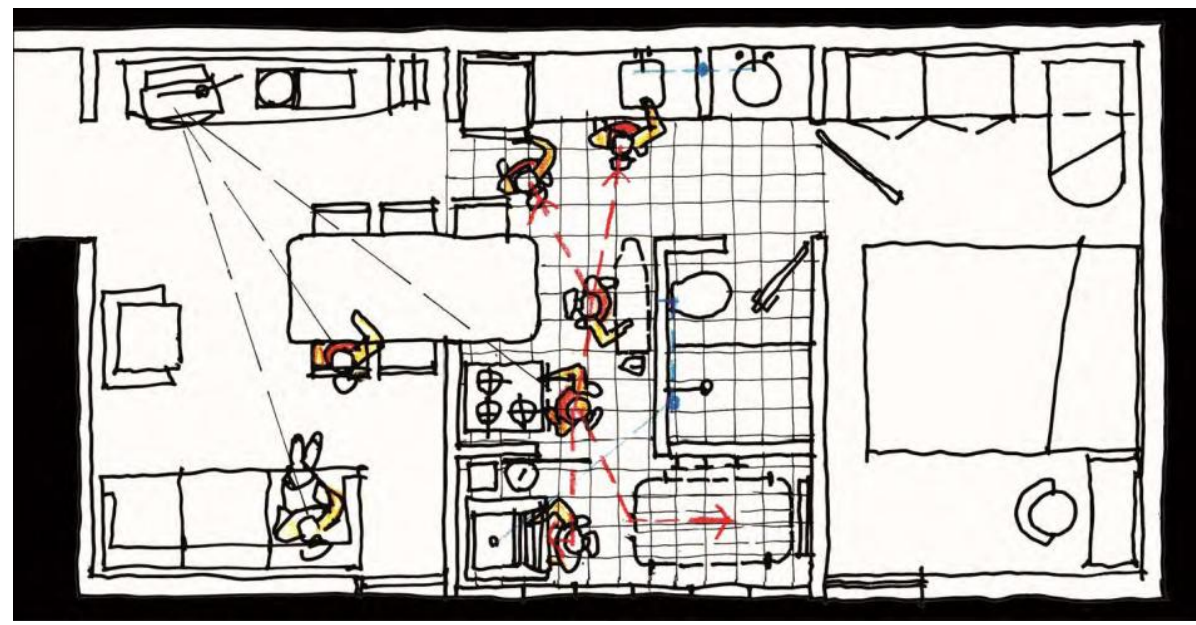

Figura 15 - Planta Tipo - Fonte: Barros (2009) - Fonte: Vigiecca \& Associados

As áreas molhadas da unidade (banheiro, cozinha e área de serviço) ocupam posição não usual - no centro da composição - fazendo a intermediação entre área social, de um lado, e área intima, do outro (figura 15). A cozinha, aberta para a sala de estar, confere ao apartamento a possibilidade de integração de espaços, conceito largamente defendido por estudiosos de projetos contemporâneos de habitação como Josep Maria Montaner (2010).

Todas as janelas dos apartamentos dos dois edifícios são voltadas para o interior do quarteirão, dada a impossibilidade de se realizar aberturas em suas partes posteriores, que, como já mencionado, estão encostadas nos limites laterais do terreno. As aberturas de iluminação e ventilação dos apartamentos também são pouco usuais: a maior janela da unidade é a da cozinha/área de serviço, enquanto as janelas da sala e do dormitório apresentam configuração mais estreita (figura 15). Esse esquema confere à fachada faixas verticais, o que, de certa maneira, se contrapõem as janelas em fita modernistas, repetidas em diversos conjuntos habitacionais do século XX.

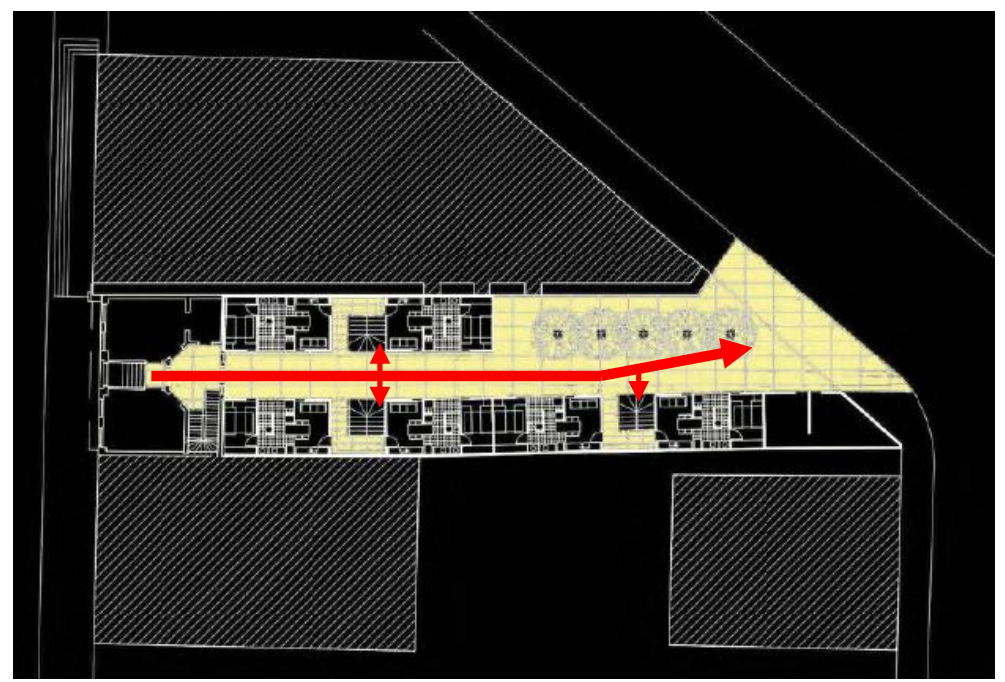

Figura 16- Circulação - Fonte: Barros (2009) - Fonte: Vigiecca \& Associados 
A entrada do conjunto pela Rua Tabatinguera apresenta grandes diferenças em relação à entrada principal do conjunto. Nesse acesso, de caráter mais aberto, o arquiteto evita o edifício entre medianeiras. Essa característica, contudo, não representa um abandono de uma estratégia de implantação mais contextual. Da Rua Tabatingüera, de acordo com o projeto, seria possível ver o edifício mais longo mimetizando-se em sua volumetria, o edifício pré-existente, localizado ao lado (figura 17).

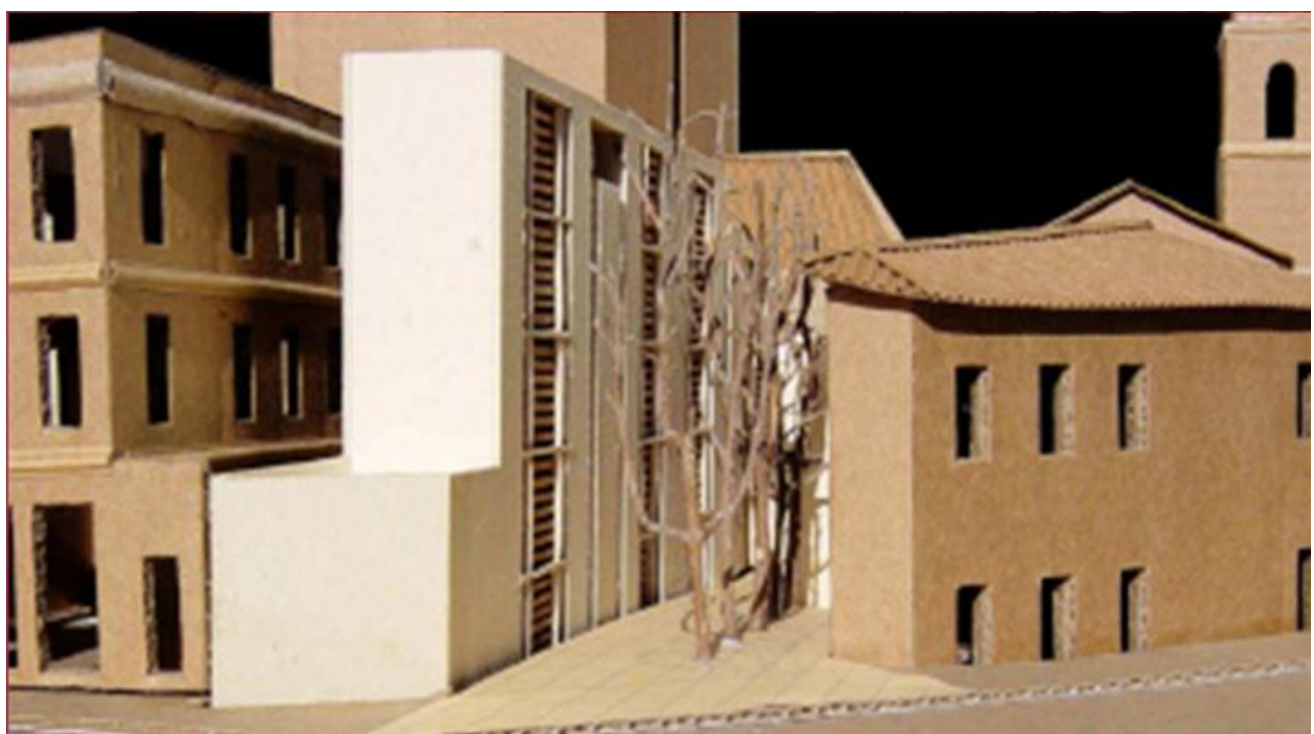

Figura 17 - Vista Rua Tabatinguera Fonte: Vigiecca \& Associados

Esse bloco (e, de fato, também o outro, contíguo à igreja), mostra a preocupação constante do arquiteto em trabalhar a relação do edifício novo com o edifício pré-existente, tanto na altura quanto no alinhamento com a rua. Assim como no projeto para a Rue des Suisses, é visível um diálogo entre arquiteturas de modo que a nova proposta não compita ou supere as alturas dos edifícios existentes, em uma atitude ao mesmo tempo de respeito com a cidade consolidada e de condicionamento do novo ao antigo.

\section{Considerações finais}

Os dois projetos estudados apresentam características que ora os aproximam, ora os distanciam. A morfologia do terreno, a proposta ou manutenção da fachada principal alinhada com a rua e contínua com as fachadas dos edifícios existentes e a circulação de pedestres no sentido longitudinal, são características que os aproximam. Por outro lado, os infinitos condicionantes presentes em um projeto de arquitetura, relativos ao programa, ao terreno, ao contexto social e histórico, às limitações legais, e, obviamente ao escritório de arquitetura contratado, são características únicas e singulares que podem dificultar o estudo paralelo das propostas, apesar das similaridades.

Como comparar projetos similares, mas ao mesmo tempo únicos? $\mathrm{O}$ arquiteto e teórico belga Richard Foqué (2010) faz algumas importantes considerações sobre o assunto. Para ele, apesar das diferenças e do caráter único de cada obra, o estudo de casos paralelos e o entendimento dos projetos estudados como respostas a condicionantes similares nos permite fazer algumas considerações que podem extrapolar os casos descritos e construir conhecimento de maneira consistente em arquitetura.

Tendo isso em mente, as considerações sobre as duas propostas analisadas neste trabalho podem lançar luz sobre estratégias projetuais possíveis no que se refere à inserção de projetos de habitação em áreas urbanas consolidadas. Algumas dessas estratégias se encontram sistematizadas 
abaixo e foram divididas em categorias (fachadas, interior do quarteirão, implantação e plantas) e acompanhadas de desenhos, plantas e fotografias.

\section{Fachadas}

Com relação às fachadas de acesso principais, os dois projetos apresentam soluções similares, propondo a continuidade do alinhamento dos edifícios pré-existentes.

No projeto de Herzog e de Meuron para o Conjunto Habitacional Rue des Suisses (projeto 1) essa continuidade é quebrada pela presença de uma dobra na fachada como resposta ao contexto e como demarcação de acessos. Essa fachada apresenta característica mutável, com a presença de uma segunda pele metálica, composta por venezianas e afastada do fechamento do edifício em vidro, conformando uma varanda entre as duas superfícies. A presença das venezianas confere à fachada um caráter aleatório e poroso, podendo ser percebida em diversas configurações, dependendo do modo com o qual as venezianas estão abertas.

Já no de Hector Vigliecca para o Casarão do Carmo (projeto 2), a fachada principal do conjunto se configura pela manutenção do edifício pré-existente, tradicional, encostado nos limites do terreno e alinhado com a rua. Essa presença do edifício histórico confere ao conjunto um caráter mais de fundo do que de figura, fazendo a nova proposta passar despercebida na paisagem, só sendo notada ao se entrar no conjunto pela Rua do Carmo ou se visto pela entrada posterior.

Os dois projetos apresentam uma segunda entrada, que no projeto 1 é semelhante à entrada principal. No projeto 2 essa entrada apresenta estratégia de projeto diferenciada, sem a presença de um edifício entre medianeiras. Localizada na parte posterior do conjunto, dá acesso público irrestrito por meio de uma passagem de pedestres que cruza o quarteirão.

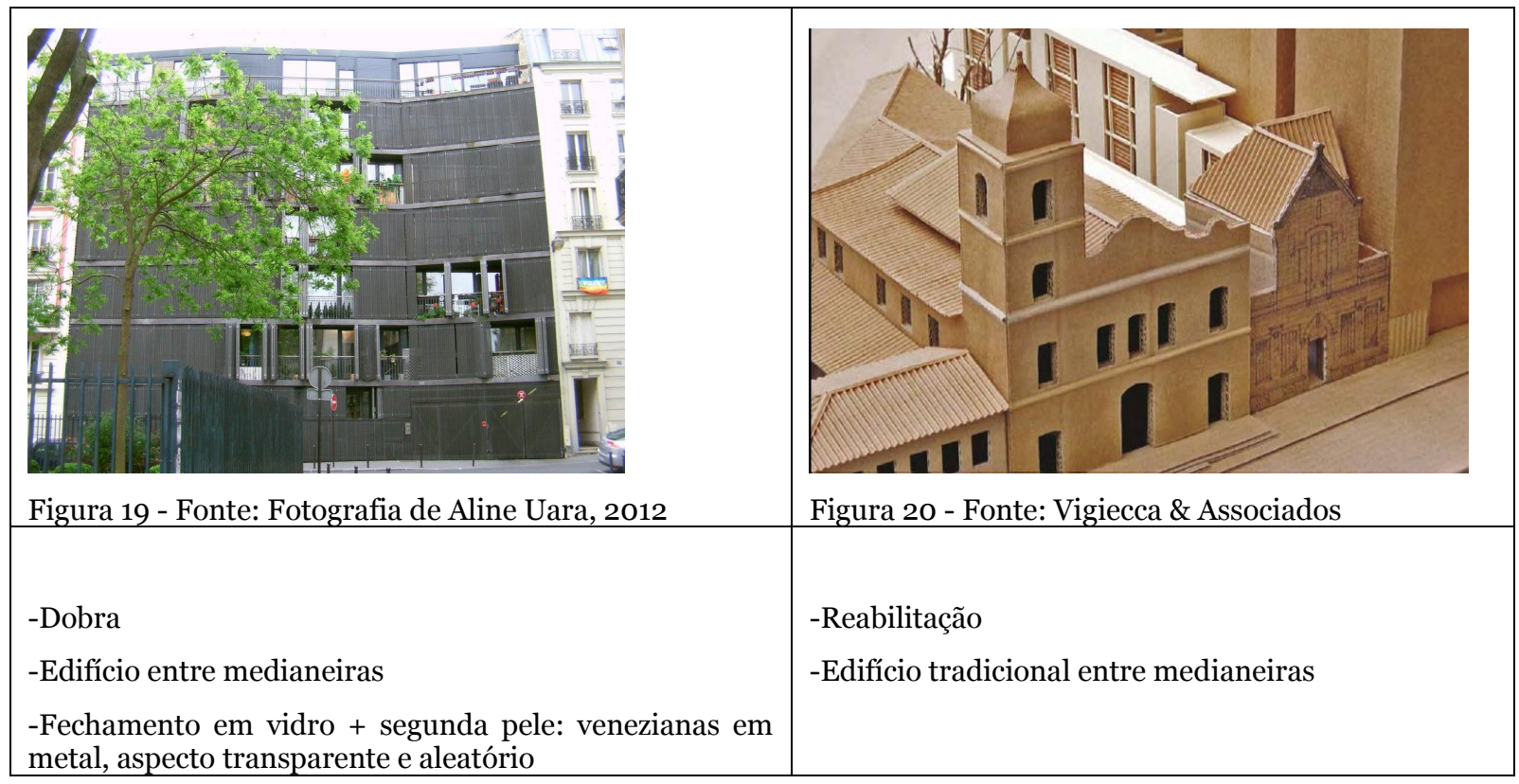

\section{Interior do quarteirão}

Com relação à circulação, os dois projetos propõem a passagem de pedestres em seu interior no sentido longitudinal do terreno. No projeto 1 a circulação acontece ao longo de um edifício horizontal. No projeto 2 ela é pública e ocorre entre dois edifícios, um mais alto e longo e outro mais baixo e curto. 
Diferentemente da circulação, o interior do lote é caracterizado de maneiras distintas nos dois projetos. No projeto 1 ele pode ser lido como um refúgio das formalidades da vida urbana, marcado pela escolha dos materiais e pela presença da natureza. No edifício 3 , ao contrário, o interior do lote é absolutamente urbano, aberto em toda a sua extensão, funcionando como uma ponto de conexão entre ruas.

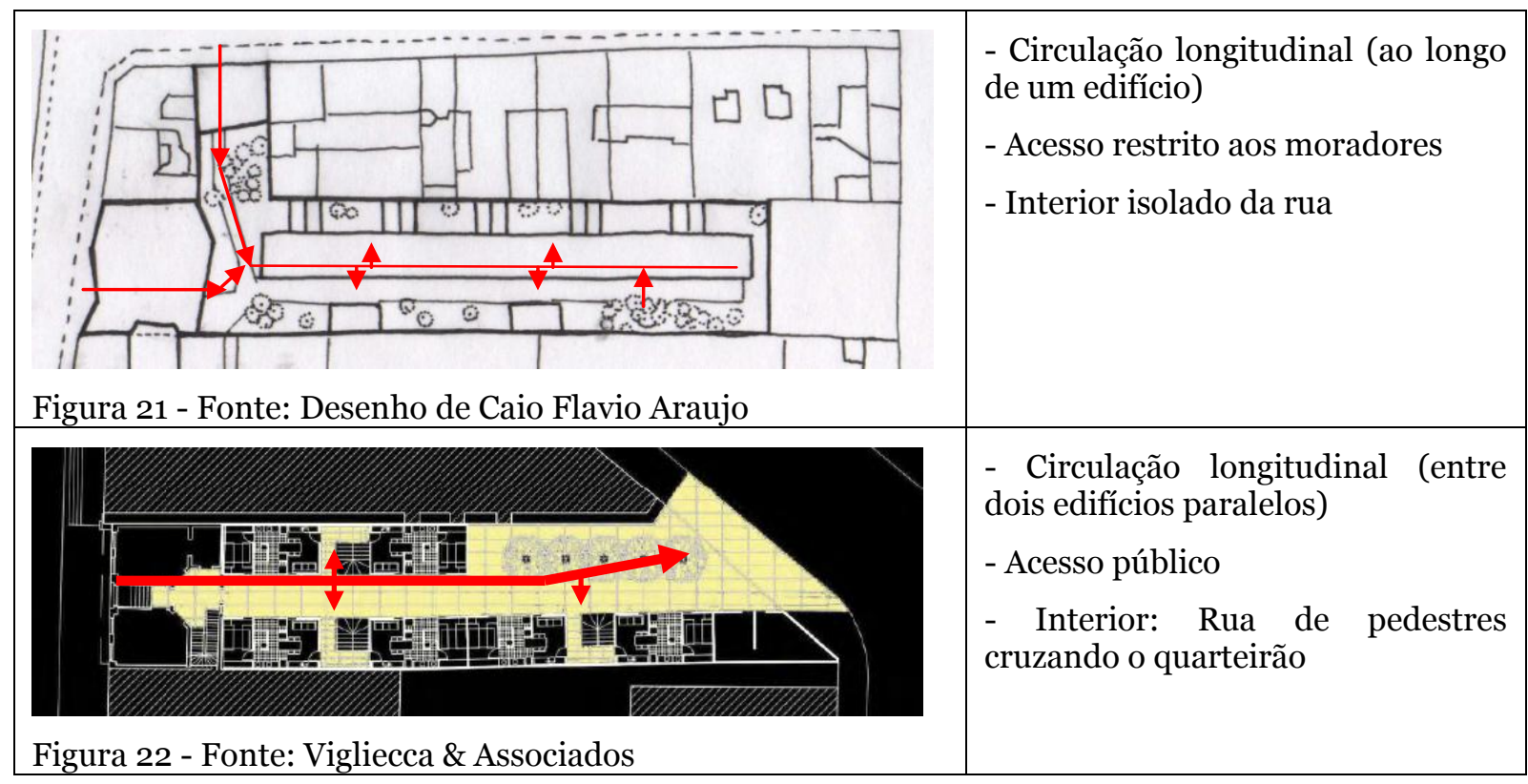

\section{Implantação:}

Nos dois projetos existe o ajuste dos gabaritos dos edifícios novos em relação às pré-existências. Como colagens urbanas ou arquiteturas que se hibridizam com a cidade, os novos edifícios se adaptam às alturas e alinhamentos dos edifícios contíguos, mimetizando, em alguns casos, sua morfologia.

No edifício 1, esses ajustes acontecem nos cinco blocos:

-Nos blocos entre medianeiras: através do alinhamento com as fachadas préexistentes, o que confere aos blocos volumetrias próximas às dos edifícios tradicionais parisienses.

-Nos pequenos volumes na parte posterior do edifício b: esses elementos conectam o grande edifício horizontal com os alinhamentos dos edifícios préexistentes, definindo o desenho da planta do pavimento térreo.

-Nas duas casas no pátio central: esses pequenos volumes estão encostados no limite do terreno.

No edifício 3, a estratégia é similar, com formalizações diferentes. A proposta se configura com a incorporação de um dos edifícios existentes ao projeto. Os novos volumes propostos estão encostados na lateral do lote e apresentam volumetrias que variam de acordo com as alturas e comprimentos dos edifícios préexistentes: um bloco mais longo de cinco andares (que se rebaixa acompanhando a volumetria dos edifícios contíguos) e um volume mais curto, de três andares ao longo do limite com a igreja do Carmo. 


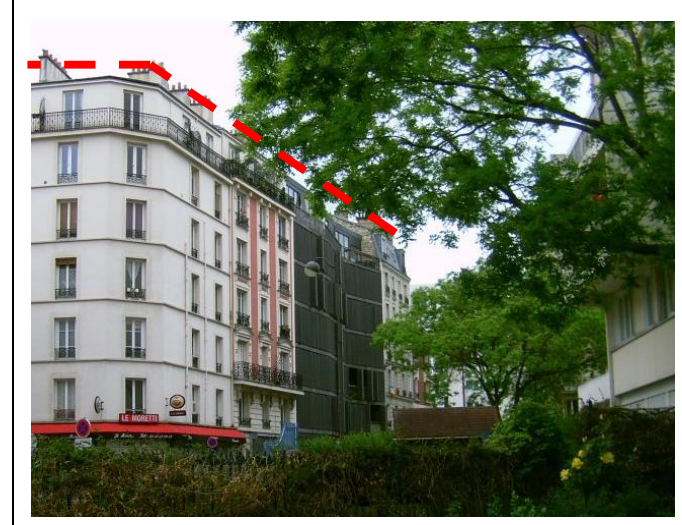

Figura 23 - Fonte: Fotografia de Aline Uara, 2012

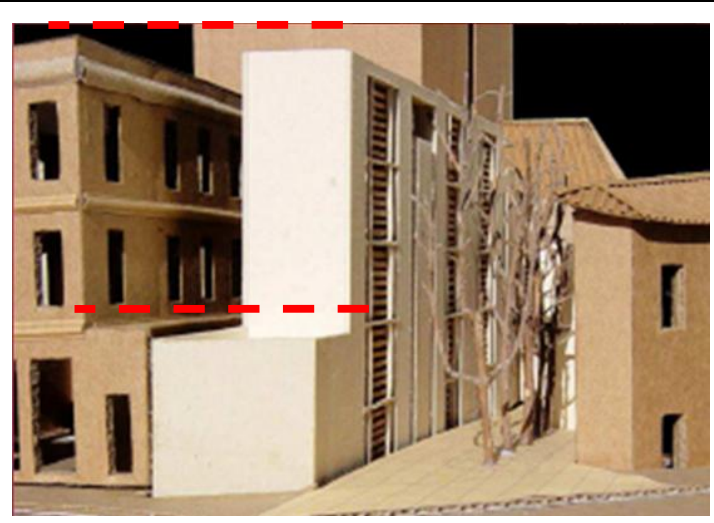

Figura 24 - Fonte: Vigliecca \& Associados

Volumetrias e gabaritos similares

HERZOG, Jacques; DE MEURON, Pierre: Gramática Urbana. Viviendas en la Rue des Suisses, Paris. In: Luis Fernández-Galiano (Ed.). Arquitectura Viva. Cohabitación Europea, 2002 possíveis para se implantar edifícios habitacionais em áreas urbanas centrais consolidadas. Propostas como o Conjunto Habitacional Rue des Suisses e o Casarão do Carmo, nos quais a conexão edifício-cidade é feita de maneira que reconheça as pré-existências, podem ser elementos geradores de mudanças, mesmo que em pequena escala, nos territórios onde estão implantadas. Mudanças estas que podem reforçar a identidade de um território e contribuir para a diminuição de diversos problemas enfrentados pelos habitantes da metrópole, transformando-a em um território mais humano e sustentável.

\section{Referências}

BARROS, Luiz Antonio Recamán; FEHR, Lucas; RUBANO, Lizete Maria: Uma ação na Cidade: Urbanização em Áreas Urbanas Críticas. São Paulo, 2009

DUBOY, P: Heterotopie: Herzog \& de Meuron, Rue des Suisses, Paris. in Architecture d'Aujourd'hui no.337: 2001

FOQUÉ, Richard. Building Knowledge in Architecture. Brussels: UPA, 2010.

JACKSON, Sarah, "Elevating The Everyday", Architectural Review, 2002.

JACOBS, Jane. The Death and Life of Great American Cities. New York: Modern Library,1993.

ROSSI, Aldo. A Arquitetura da Cidade. São Paulo: Martins Fontes, 1995.

ROWE, Colin. Collage City. Cambridge, Mass: MIT Press, 1984. 